\title{
The conservatism and uncertainty in a regulatory model for predicting derived release limits for aquatic emissions
}

\author{
S.L. Chouhan and P.A. Davis \\ AECL, Chalk River Laboratories, Chalk River, Ontario KOJ 1Jo, Canada
}

\begin{abstract}
The conservatism and uncertainty in the Canadian Standards Association (CSA) model for calculating derived release limits (DRLs) for aquatic emissions of radionuclides from nuclear facilities was investigated. The model was run deterministically using the recommended default values for its parameters and its predictions were compared with the distributed doses obtained by running the model stochastically. Median doses from 400 stochastic runs were higher than the deterministic doses predicted using CSA default values for more than half of the radionuclides considered. Thus the CSA model is not always conservative for calculating DRLs for aquatic emissions as it was intended to be. The uncertainty in the predicted ingestion dose was high, with the $95 \%$ confidence interval exceeding an order of magnitude for most radionuclides. A sensitivity study revealed that ingestion doses to adults predicted by the CSA model are sensitive primarily to water intake rates, bioaccumulation factors for fish and marine biota, dietary intakes of fish and marine biota, the fraction of consumed food arising from contaminated sources and irrigation rate. To improve DRL models, further research in aquatic exposure pathways should concentrate on reducing the uncertainty in these parameters.
\end{abstract}

\section{INTRODUCTION}

Screening and regulatory models have traditionally been designed to overestimate doses in order to protect members of the public. This is the case for the Canadian Standards Association model CSAN288.1 [1], which provides guidelines for calculating derived release limits (DRLs) for routine emissions at nuclear facilities. However, the exact level of conservatism in N288.1 is unknown. The best way to establish the level is to compare model predictions with environmental measurements, but this is difficult because suitable data are rare. An alternative is to compare the deterministic prediction of the model with the range of predictions that arises from a probabilistic analysis. The location of the deterministic result in the output distribution provides an indication of the conservatism in the model.

In this paper, deterministic doses calculated using the default parameter values recommended in CSA-N288.1 were compared with stochastic results for 28 radionuclides released routinely from CANDU reactors in liquid effluent to aquatic systems. The stochastic calculations were carried out using distributions of parameter values from the literature tuned to Canadian CANDU sites. The stochastic results were used to determine the $95 \%$ confidence interval in the predictions of N288.1 and to identify the parameters and pathways that contribute most to the uncertainty, as a means to setting priorities for future work.

The CSA model is a standard equilibrium compartment model. Liquid effluents contaminate the receiving water body, its sediments and any animals and plants living in it. Members of the public receive ingestion doses by consuming water and aquatic foods, immersion doses by swimming or bathing in the water, and external doses from exposure to contaminated beaches. Terrestrial soils and plants may also become contaminated via imigation, leading to additional ingestion and groundshine doses. Specific activity models are used for tritium and ${ }^{14} \mathrm{C}$. 


\section{PARAMETER VALUES AND DISTRIBUTIONS}

Parameter values were found from a number of sources: published papers and reports identified through literature reviews, consultation with recognized experts in the field, DRL reports, site-specific surveys and compendia of parameter values, including those developed in other AECL projects [2,3]. In all, about 150 papers and reports were consulted in gathering parameter values.

For most parameters, the number of experimental values found was less than 20 . This was not enough to determine the form of the distribution or to calculate the standard deviation directly from the data itself. Instead, the distributions were set largely by judgment, using whatever data were available, distributions suggested in the literature and expert consultation. Mean values were set using the most recent, applicable publications. Some sources provided maximum and minimum values, which were helpful in setting standard deviations.

Radionuclide concentrations in water at the receptor were assumed known since aquatic dispersion is too site-specific to be treated in a generic way in a probabilistic model. These concentrations were fixed at nominal but realistic values that were equal for all radionuclides apart from decay and ingrowth over an assumed travel time of one day from source to point of water use. The use of fixed concentrations means that the uncertainties in the doses reported below are likely to be underestimated. The fixed values also prevent the parameters in the aquatic dispersion model from appearing among the parameters to which the overall DRL model is sensitive.

Distributions for the parameters required in the aquatic pathways of N288.1 (irrigation rate, water intake rates by animals, bioaccumulation factors (BAFs), fish consumption rates by humans and so on) are documented by Chouhan and Davis [4]. Distributions for parameters in the terrestrial pathways were taken from Peterson [5]. A report by Chant et al. [6] provided useful data on transfer parameters to freshwater fish and to marine fish and biota (crustacea, molluscs and seaweed) at Canadian CANDU sites. Since concentrations of radioactive elements are mostly below detection level, these BAFs were derived from measurements of stable element concentrations. Measurements were made for $\mathrm{Cr}, \mathrm{Mn}, \mathrm{Fe}$, $\mathrm{Co}, \mathrm{Zn}, \mathrm{Sr}, \mathrm{Zr}, \mathrm{I}, \mathrm{Cs}, \mathrm{Ba}$ and $\mathrm{Ce}$. Because of its extent, quality and relevance to Canadian conditions, these data were used preferentially to define BAF values for this study. The values for each element were assumed to be lognormally distributed and geometric means were calculated from pooled data from all sites for the aquatic species in question (Table 1). A different philosophy was adopted for the geometric standard deviations (GSDs). The use of pooled data here led to large GSDs that are believed to be unrepresentative of the variance in individual water bodies, to which DRL models are applied in practice. Instead, separate GSDs were calculated from the values available for each element for each aquatic species in each water body. A single representative GSD of 2.5 was then chosen for freshwater fish and used for each radionuclide on the assumption that the variability is the same for each element in each water body. A GSD of 3.0 was used for all marine species. Geometric means for elements not included in the study of Chant et al. [6] were constructed from data published in the literature.

Site-specific data suggest that most adults living near CANDU reactors in Canada never eat fish. Accordingly, the distribution for fish consumption was assumed to be piecewise uniform, with $75 \%$ of adults eating no fish, $20 \%$ eating fish once a week and the remaining $5 \%$ eating fish almost every day. Ingestion rates of fish by infants and of crustacea, molluses and seaweed by adults and infants were normally distributed based on available data and judgement.

\section{Calculations}

Uncertainty and sensitivity analyses were carried out for fresh water and marine scenarios. In each case, whole body effective doses to adults and one-year old infants were calculated due to ingestion, groundshine and immersion. Only the results for ingestion doses are discussed here; complete resilts are presented in Chouhan and Davis [4]. The model was run 400 times with parameter values drawn from their distributions in each run using Latin Hypercube sampling [7]. Doses at the 2.5 percentile, median and 97.5 percentile of the output distribution were determined. The model was also run in its 
deterministic mode using the default parameter values from N288.1 to produce default doses. The locations of these doses in the output distributions were determined. Partial correlation and standardized regression coefficients were calculated from the input values and output doses [8] to determine the sensitivity of the model to each parameter.

Table 1. Geometric mean values of bioaccumulation factors for freshwater fish flesh, marine fish flesh, crustacea, molluscs and seaweed ( $\mathrm{L} \mathrm{kg}^{-1}$ wet weight). All values are based on unfiltered water. The geometric standard deviation is 2.5 for freshwater fish and 3.0 for all other species.

\begin{tabular}{|c|c|c|c|c|c|}
\hline Nuclide & Freshwater Fish & Marine Fish & Crustacea & Mölluscs & Seaweed \\
\hline $\mathrm{H}$ & ${ }^{*} 1.0$ & $1.0^{*}$ & $* 1.0$ & $* 1.0$ & $* 1.0$ \\
\hline $\mathrm{C}$ & $5.7 \times 10^{3}$ & $2.0 \times 10^{3}$ & $2.0 \times 10^{4}$ & $2.0 \times 10^{4}$ & $1.0 \times 10^{4}$ \\
\hline $\mathrm{Cr}$ & $5.3 \times 10^{1}$ & $4.0 \times 10^{2}$ & $5.0 \times 10^{2}$ & $8.0 \times 10^{2}$ & $2.0 \times 10^{3}$ \\
\hline $\mathrm{Mn}$ & $1.2 \times 10^{2}$ & $1.8 \times 10^{2}$ & $1.7 \times 10^{3}$ & $2.5 \times 10^{2}$ & $1.3 \times 10^{4}$ \\
\hline $\mathrm{Fe}$ & $3.8 \times 10^{1}$ & $3.0 \times 10^{3}$ & $5.0 \times 10^{3}$ & $3.0 \times 10^{4}$ & $3.0 \times 10^{4}$ \\
\hline $\mathrm{Co}_{0}$ & $7.0 \times 10^{1}$ & $1.0 \times 10^{3}$ & $9.8 \times 10^{3}$ & $5.0 \times 10^{3}$ & $3.3 \times 10^{4}$ \\
\hline $\mathrm{Zn}$ & $2.6 \times 10^{3}$ & $2.0 \times 10^{4}$ & $2.7 \times 10^{5}$ & $6.5 \times 10^{4}$ & $1.4 \times 10^{5}$ \\
\hline St & $2.2 \times 10^{0}$ & $1.0 \times 10^{-1}$ & $1.8 \times 10^{0}$ & $2.2 \times 10^{-1}$ & $4.7 \times 10^{0}$ \\
\hline $\mathrm{Zr}$ & $1.5 \times 10^{1}$ & $1.0 \times 10^{2}$ & $2.0 \times 10^{2}$ & $5.0 \times 10^{3}$ & $3.0 \times 10^{3}$ \\
\hline $\mathrm{Nb}$ & $3.0 \times 10^{2}$ & $1.0 \times 10^{2}$ & $2.0 \times 10^{2}$ & $1.0 \times 10^{3}$ & $3.0 \times 10^{3}$ \\
\hline Mo & $4.7 \times 10^{n}$ & $4.4 \times 10^{0}$ & $3.2 \times 10^{0}$ & $1.0 \times 10^{2}$ & $2.7 \times 10^{1}$ \\
\hline $\mathrm{Ru}$ & $1.0 \times 10^{1}$ & $1.0 \times 10^{1}$ & $1.0 \times 10^{2}$ & $2.0 \times 10^{3}$ & $2.0 \times 10^{3}$ \\
\hline $\mathrm{Te}$ & $4.0 \times 10^{2}$ & $4.0 \times 10^{3}$ & $1.0 \times 10^{3}$ & $1.0 \times 10^{3}$ & $1.0 \times 10^{4}$ \\
\hline I & $4.3 \times 10^{1}$ & $1.0 \times 10^{1}$ & $1.0 \times 10^{1}$ & $1.0 \times 10^{1}$ & $1.0 \times 10^{3}$ \\
\hline $\mathrm{Cs}$ & $6.0 \times 10^{3}$ & $7.9 \times 10^{1}$ & $1.5 \times 10^{1}$ & $1.4 \times 10^{1}$ & $2.2 \times 10^{2}$ \\
\hline $\mathrm{Ba}$ & $1.0 \times 10^{0}$ & $1.0 \times 10^{1}$ & $1.6 \times 10^{1}$ & $1.9 \times 10^{0}$ & $9.9 \times 10^{1}$ \\
\hline $\mathrm{Ce}$ & $4.0 \times 10^{\circ}$ & $3.0 \times 10^{2}$ & $1.0 \times 10^{3}$ & $5.0 \times 10^{3}$ & $5.0 \times 10^{3}$ \\
\hline
\end{tabular}

* Fixed value.

\section{RESULTS OF THE UNCERTAINTY ANALYSIS}

Results of the uncertainty analysis for adult ingestion dose for releases to fresh water are shown in Figure 1. Because $75 \%$ of adults do not eat fish, the median of the output distribution reflects the dose received by a non-fish eater. This explains why the median lies below the midpoint of the $95 \%$ confidence interval for many nuclides.

For five of the 28 radionuclides $\left({ }^{55} \mathrm{Fe},{ }^{59} \mathrm{Fe},{ }^{90} \mathrm{Sr},{ }^{125 m} \mathrm{Te}\right.$ and $\left.{ }^{129} \mathrm{I}\right)$, the deterministic doses calculated using CSA N288.1 default parameters lie below the median of the stochastic doses. N288.1 cannot be considered conservative for these radionuclides. Default doses for most of the remaining radionuclides hie near the $60^{\text {th }}$ or $70^{\text {th }}$ percentile of the output distribution, a reasonable level of conservatism. Four radionuclides $\left({ }^{3} \mathrm{H},{ }^{14} \mathrm{C},{ }^{99} \mathrm{Mo}\right.$ and $\left.{ }^{133} \mathrm{I}\right)$ are located at or above the $90^{\mathrm{th}}$ percentile, which is overly conservative.

The highest median doses on a per unit release basis are given by ${ }^{129} \mathrm{I}$ and ${ }^{90} \mathrm{Sr}$. Both these radionuclides are long-lived and have high ingestion dose coefficients, and for both the dose comes in equal parts from ingestion of water and terrestrial foods. The lowest median doses are given by tritium and ${ }^{51} \mathrm{Cr}$. For both these nuclides, $70-90 \%$ of the dose comes from water intake, $10-20 \%$ from terrestrial crops and a small percentage from fish consumption. Tritium has the lowest BAF value of all radionuclides and ${ }^{S 1} \mathrm{Cr}$ is among the lowest. Ingestion dose coefficients are low for both nuclides.

The largest $95 \%$ confidence intervals occur for ${ }^{136} \mathrm{Cs}$ and ${ }^{134} \mathrm{Cs}$. The dose for both these radionuclides is dominated by fish ingestion and the distribution for the BAF covers three orders of magnitude. The smallest confidence intervals occur for tritium and ${ }^{99} \mathrm{Mo}$. For ${ }^{99} \mathrm{Mo}, 92 \%$ of the dose comes from water intake, which has relatively low uncertainty. Water intake is also important for tritium and the $\mathrm{BAF}$ is assumed to have no uncertainty for this radionuclide. 
The N288.1 model is less conservative for infants than for adults as default doses for 11 radionuclides lie below the median of their respective output distributions. The magnitudes of the doses are slightly larger for infants than for adults because infants consume more water (mixed with powdered milk).

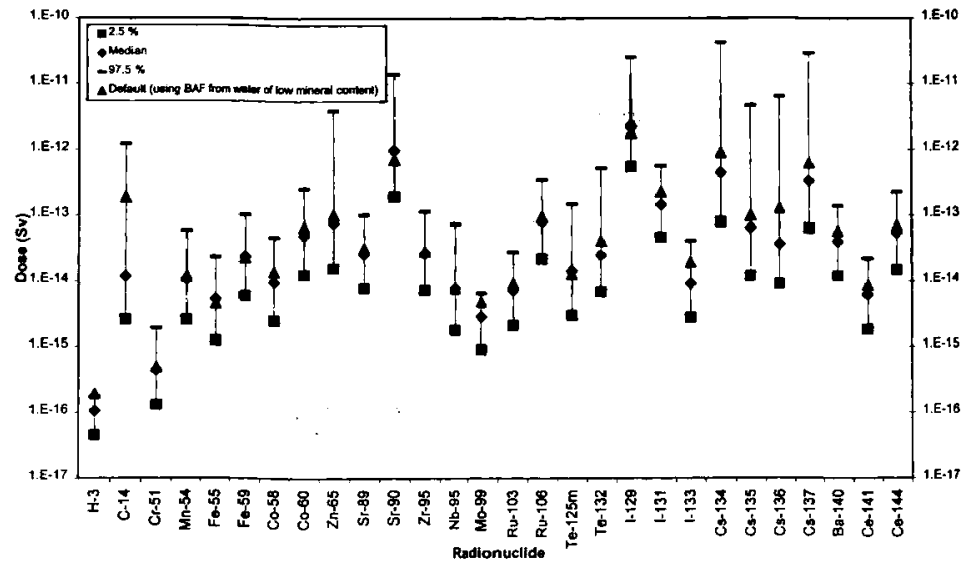

Figure 1: Adult ingestion dose for the freshwater environment for a unit release.

For releases to marine water bodies, drinking water and terrestrial compartments do not become contaminated and the ingestion dose comes simply from consumption of marine fish and biota. For both adults and infants, the default dose using N288.I parameter values is below the median dose from the stochastic calculations for 13 radionuclides. For many of these $\left({ }^{14} \mathrm{C},{ }^{58} \mathrm{Co},{ }^{60} \mathrm{Co},{ }^{65} \mathrm{Zn},{ }^{95} \mathrm{Zr},{ }^{95} \mathrm{Nb},{ }^{103} \mathrm{Ru}\right.$, ${ }^{106} \mathrm{Ru},{ }^{141} \mathrm{Ce}$ and ${ }^{144} \mathrm{Ce}$ ), the default lies close to the lower end of the $95 \%$ confidence interval, indicating that the N288.1 model strongly underestimates marine ingestion doses for these radionuclides.

The highest median dose for the marine case was given by ${ }^{65} \mathrm{Zn}$, which has the highest BAFs of all radionuclides for all marine species. The lowest median dose was given by tritium, which has a low bioaccumulation factor. Doses from strontium were also low, in contrast to the case for the fresh water environment, where they were among the highest because of contributions from drinking water and terrestrial crops, which are not important here. Ingestion doses in the marine environment are higher than those in fresh water because of seafood ingestion.

Confidence intervals are smaller (less than two orders of magnitude) for marine doses than for freshwater doses because there are fewer pathways and parameters in the marine case. A somewhat larger range occurred for nuclides for which the dose is dominated by a single species (e.g. molluscs in the case of ${ }^{99} \mathrm{Mo}$ ). The uncertainties in the tritium doses are low because the bioaccumulation factors for this radionuclide are assumed to have no uncertainty. 


\section{RESULTS OF THE SENSITIVITY ANALYSIS}

Seven radionuclides $\left({ }^{3} \mathrm{H},{ }^{14} \mathrm{C},{ }^{90} \mathrm{Sr}_{8}{ }^{95} \mathrm{Nb},{ }^{106} \mathrm{Ru},{ }^{13 !} \mathrm{I}\right.$ and $\left.{ }^{137} \mathrm{Cs}\right)$ were selected for sensitivity analysis. These nuclides have release rates that are among the highest from CANDU reactors and show a wide variety of behaviours in the environment. For each nuclide, Table 2 lists the parameters that have the largest effect on the predicted ingestion dose for the entire adult population (fish-eaters and non-fisheaters combined) for releases to fresh water. The dose for tritium, which does not accumulate in the environment, comes primarily via drinking water and is most sensitive to the parameters in the drinking water pathway. Doses from ${ }^{90} \mathrm{Sr},{ }^{106} \mathrm{Ru}$ and ${ }^{131} \mathrm{I}$, which have relatively low BAFs but are readily taken up by crops, are dominated by ingestion of terrestrial crops and are most sensitive to parameters such as irrigation rate and the fraction of activity initially retained on vegetation following irrigation. On the other hand, doses from ${ }^{14} \mathrm{C},{ }^{95} \mathrm{Nb}$ and ${ }^{137} \mathrm{Cs}$ are most sensitive to the consumption rate for fish. The BAF itself does not appear as a sensitive parameter in Table 2. This is because the results apply to a population in which $75 \%$ of the people eat no fish at all. When only fish eaters are considered, the BAF becomes the most sensitive parameter for ${ }^{14} \mathrm{C}$ and ${ }^{137} \mathrm{Cs}$ and ranks among the top three for ${ }^{95} \mathrm{Nb}$ and ${ }^{131} \mathrm{I}$, and doses are dominated by fish ingestion.

For releases to the marine environment, ingestion doses are generally most sensitive to the BAF for one or the other of molluscs, crustacea, fish or seaweed, depending on the radionuclide. The fraction of aquatic food that is contaminated is also an important parameter, followed by the consumption rates of the various species. Results for infants are similar to those for adults for both fresbwater and marine cases.

Table 2. The parameters to which predicted ingestion doses are most sensitive for the entire adult population for release to fresh water. Partial correlation coefficients are shown in parentheses.

\begin{tabular}{|c|c|c|c|c|}
\hline Radionuclide & $\overline{\mathrm{i}}^{\mathrm{st}}$ parameter & $2^{\text {th }}$ parangeter ${ }^{*}$ & $3^{\text {re }}$ parameter & Dominating Pathway \\
\hline${ }^{3} \mathrm{H}$ & $\mathrm{f}_{\mathrm{dw}}(0.96)$ & $I_{d w}(0.89)$ & $f_{\text {veg }}(0.52)$ & Drinking water \\
\hline${ }^{14} \mathrm{C}$ & $I_{\text {Esh }}(0.89)$ & $\mathrm{R}_{\mathrm{irr}}(0.75)$ & $f_{\text {ret }}(0.44)$ & Fish consumption \\
\hline${ }^{90} \mathrm{~S} r$ & $\mathrm{C}_{\mathrm{r}}(0.83)$ & $\mathrm{R}_{\mathrm{ir}}(0.63)$ & $f_{\text {yeg }}(0.47)$ & $\begin{array}{l}\text { Consumption of crops } \\
\text { contam inated via root uptake }\end{array}$ \\
\hline${ }^{95} \mathrm{Nb}$ & $I_{\text {filsh }}(0.79)$ & $\mathrm{R}_{\mathrm{irr}}(0.79)$ & $f_{\text {ret }}(0.56)$ & Fish consumption \\
\hline${ }^{106} \mathrm{Ru}$ & $\mathbf{R}_{\text {iा }}(0.87)$ & $\mathrm{f}_{\mathrm{TN}}(0.67)$ & $\mathrm{f}_{\text {veg }}(0.59)$ & $\begin{array}{l}\text { Consumption of crops directly } \\
\text { contaminated via imigation }\end{array}$ \\
\hline${ }^{131} \mathrm{I}$ & $R_{\text {ur }}(0.77)$ & $f_{d w}(0.75)$ & $I_{\text {fish }}(0.65)$ & $\begin{array}{l}\text { Consumption of crops directly } \\
\text { contaminated via irrigation }\end{array}$ \\
\hline${ }^{137} \mathrm{Cs}$ & $I_{t \leq s h}(0.89)$ & $\mathbf{R}_{\mathrm{ir}}(\mathbf{0 . 7 4})$ & & Fish consumption \\
\hline
\end{tabular}

* $f_{\mathrm{du}}=$ fraction of drinking water from the contaminated source; $I_{\mathrm{fteh}}=$ intake rate of fish; $\mathrm{C}_{\mathrm{f}}=$ plant/soil concentration ratio; $R_{\text {irr }}=$ irrigation rate; $I_{d w}=$ intake rate of drinking water; $f_{\text {ret }}=$ fraction of activity initially retained on vegetation following irrigation; $f_{\text {veg }}=$ fraction of vegetation from the contaminated source.

\section{CONCLUSIONS}

The default parameter values given in CSA N288.1 are not always conservative. In about half the cases considered here, they were lower than the median values of the corresponding distributions. In these cases, doses predicted using the default values lay below the median of the calculated dose distribution and were also not conservative. The same is likely true of regulatory models used in other countries. The model underestimated doses less often for the freshwater case than for the marine case, likely because there were more data on which to base freshwater default parameters at the time when the CSA model was issued.

The uncertainties in the predicted ingestion doses varied from radionuclide to radionuclide, but the $95 \%$ confidence interval for the freshwater case usually exceeded an order of magnitude and 
occasionally two orders of magnitude. Confidence intervals were smaller for marine doses because there are many fewer pathways and parameters compared to the freshwater case.

The parameters to which the predicted ingestion doses are most sensitive depend upon the radionuclide. Doses for nuclides that have relatively low BAFs but are readily taken up by crops are most sensitive to parameters in the terrestrial pathways. On the other hand, ingestion doses for nuclides with large BAFs are most sensitive to bioaccumulation factors and consumption rates of aquatic organisms, at least for those members of the population who eat fish. Drinking water is generally not an important pathway except for tritium and, to some extent, iodine. Uncertainties in predicted ingestion doses will be reduced most effectively by focussing future work on establishing site-specific values for parameters such as water intake rates, bioaccumulation factors, dietary intake rates for fish and marine biota, irrigation rates, and the fraction of consumed food arising from contaminated sources.

Groundshine doses are comparable to ingestion doses and depend strongly on the soil and sediment solid/liquid distribution coefficients. These coefficients have large associated uncertainty and would benefit from additional experimental work, particularly in the case of sediments. Immersion doses are much lower than groundshine or ingestion doses and can be given low priority in future work.

\section{References}

[1] Canadian Standards Association, "Gujdelines for calculating derived release limits for radioactive material in airborne and liquid effluents for normal operation of nuclear facilities", Canadian Standards Association, CAN/CSA-N288.1-M87 (1987).

[2] Davis P.A., Zach R., Stephens M.E., Amiro B.D., Bird G.A., Reid J.A.K., Sheppard M.I., Sheppard S.C. and Stephenson M., "The disposal of Canada's nuclear fuel waste: The biosphere model, BIOTRAC, for postclosure assessment", AECL-10720, COG-93-10 (1993).

[3] Zach R. and Sheppard S.C., "The food-chain and dose model, CALDOS, for accessing Canada's nuclear fuel waste management concept", AECL-10165, COG-91-195 (1992).

[4] Chouhan S.L. and Davis P.A., "Doses from aquatic pathways in CSA-N288.1: Deterministic and stochastic predictions compared", AECL report in preparation (2001).

[5] Peterson S-R., "Doses from terrestrial pathways in CSA-N288. 1: Deterministic and stochastic predictions compared", COG-98-239-I (1998).

[6] Chant L.A., Hartwig D.S. and Totland M., "Site-specific aquatic transfer factors for CANDU sites in Canada", RC-2457, AECL (2000).

[7] Iman R.L. and Shortencarier M.J., "A FORTRAN 77 program and user's guide for the generation of Latin hypercube and random samples for use with computer modets", NUREG/CR-3624, Sandia National Laboratories, Albuquerque, NM (1984).

[8] Iman R.L., Shortencarier M.J. and Johnson J.D., "A FORTRAN 77 program and user's guide for the calculation of partial correlation and standardized regression coefficients", NUREG/CR-4122 (SAND850044), Sandia National Laboratories, Albuquerque, NM (1985). 